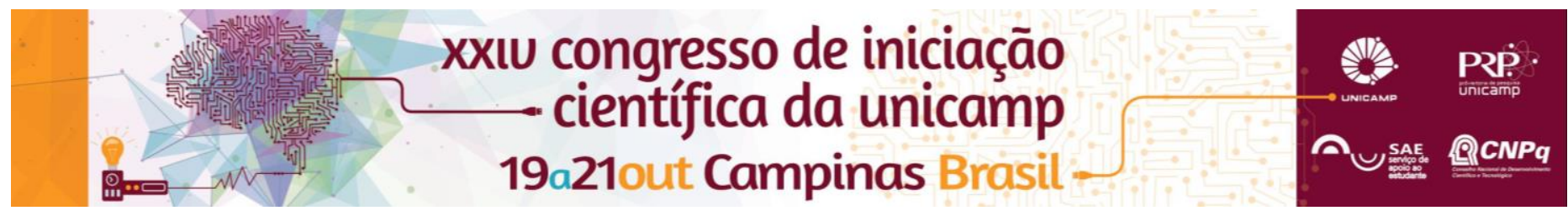

\title{
"Estudo e Planejamento de um Programa de Coleta Seletiva e Compostagem de Resíduos de Poda e Capina na Faculdade de Tecnologia."
}

\author{
Bruna Costa*, Carmenlucia S. Giordano Penteado.
}

\begin{abstract}
Resumo
O conceito de sustentabilidade e ambientes sustentáveis vem se tornando algo frequente na atualidade e dessa maneira o gerenciamento adequado dos resíduos sólidos gerados dentro de uma universidade se faz necessário para a harmonização com tais conceitos. Nesta pesquisa foi realizado um estudo sobre os resíduos sólidos gerados no Campus I da UNICAMP de Limeira, com intuito da implantação de um programa de coleta seletiva e compostagem de resíduos de poda e capina de forma contínua, nas áreas vinculadas à Faculdade de Tecnologia (FT). Foi realizada a caracterização dos resíduos, e com base nestes dados elaborado e implantado o programa, que foi monitorado durante todo o período deste projeto.
\end{abstract}

\section{Palavras-chave:}

Gerenciamento de resíduos, compostagem, coleta seletiva.

\section{Introdução}

Para tornar o campus um lugar mais sustentável, entre outras coisas, é fundamental entender como o Gerenciamento de Resíduos Sólidos (GRS) está sendo realizado. O GRS é um instrumento que coopera na redução de resíduos dispostos em aterros sanitários ${ }^{1}$. Para tanto, o primeiro passo envolve a caracterização dos resíduos gerados, de forma a quantificar o total gerado, a composição e as fontes de geração. Com base nos resultados da caracterização é possível realizar todo o planejamento de um sistema de gerenciamento de resíduso sólidos.

Nesta pesquisa foi realizada a caracterização dos resíduos gerados na Faculdade de Tecnologia (Campus I de Limeira), visando a implantação de um programa de coleta seletiva, e um projeto piloto de compostagem dos resíduos de poda e capina (resíduos verdes), gerados na limpeza das áreas externas do campus.

\section{Resultados e Discussão}

Foram feitas duas caracterizações dos resíduos comuns, uma inicial (Fig.1a) e outra após a colocação adoção de canecas em substituição a copos descartáveis e de coletores diferenciados para recicláveis (Fig. 1b). Esses resultados mostram que não houve significativa redução de recicláveis junto ao lixo comum, após a adoção das medidas, evidenciando a necessidade de capacitação dos funcionários da limpeza e conscientização de todos os usuários do campus sobrea importância da segregação.

Figura 1. Caracterização dos resíduos antes (a) e depois (b) da adoção de caixas para separação de recicláveis.
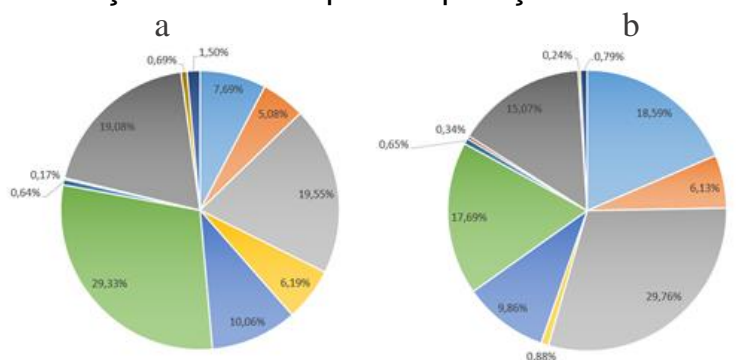

Em relação aos resíduos de poda e capina, foi montada uma pilha de compostagem experimental, com o material resultante de uma das operações de limpeza externas do campus do ano de 2016. Para tanto, utilizou-se cerca de $1 \mathrm{~m} 3$ de material, que foi constantemente revolvido para oxigenação, umedecido com água e teve a temperatura monitorada. Notou-se um excelente desenvolvimento da temperatura e do processo de compostagem (Fig. 2).

Figura 2. Variação de temperatura (ambiente, média da base e no centro) da composteira de resíduos verdes.
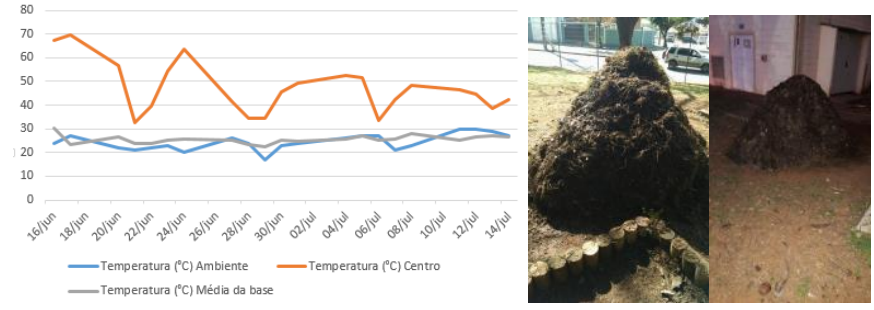

\section{Conclusões}

A caracterização dos resíduos gerados na FT mostrou que não há uma preocupação com a redução da geração de resíduos segregação dos materiais recicláveis. Mesmo com a implementação de novas lixeiras (cor cinza para rejeitos e azul para recicláveis), e distribuição de canecas a todos os docentes e funcionários da FT, ainda verifica-se um grande descarte de copos plásticos, e de materiais recicláveis junto ao lixo comum. Tal constatação reforça a necessidade de um trabalho mais focado na capacitação e conscientização de todos os usuários do campus.

Em relação aos resíduos verdes, a compostagem se mostrou perfeitamente viável, e apresenta potencial para que seja implantado um sistema para compostar todo o resíduo verde gerado, o que será sugerido à planta física.

\section{Agradecimentos}

Ao PIBIC/CNPq pela bolsa; às colaboradoras da limpeza no campus I de Limeira, e à Planta Física de Limeira.

${ }^{1}$ Silva, Jose Rodrigo dos Santos; COELHO, Brunna Evelyn Nogueira. Plano De Gerenciamento De Resíduos Sólidos De Uma Instituição De Ensino Superior Do Estado De Goiás. In: Congresso Brasileiro De Gestão Ambiental, 3., 2012, Goiâna: Instituto Brasileiro de Estudos Ambientais, 2012. p. 1 - 7. 